\title{
PERCEIVED ATTRIBUTES OF HURRICANE-RELATED RETROFITS AND THEIR EFFECT ON HOUSEHOLD ADOPTION
}

\author{
A Thesis \\ Presented to the Faculty of the Graduate School \\ of Cornell University \\ In Partial Fulfillment of the Requirements for the Degree of \\ Master of Science
}

by

Yilin Zou

2020 May 
(C) 2020 Yilin Zou 


\begin{abstract}
Understanding how homeowners make protective action decisions is important for designing policies and programs to encourage those actions and community resilience as a whole. This thesis focuses on the role of homeowner perceptions of attributes of the protective actions themselves in influencing household protective action decisions. Specifically, using a combination of revealed and stated preference data from a mailed survey of homeowners in North Carolina, we fitted mixed logit models to predict the probability a homeowner has or intends to structurally retrofit (strengthen) her home to mitigate hurricane wind and flood damage. We found evidence supporting the hypotheses that a higher probability of undertaking a retrofit is associated with homeowner beliefs that: (1) the retrofit cost is not too high, (2) the installation does not require too much effort, (3) they understand how it works, (4) it would add to home value, (5) it would protect lives, (6) it would protect property, and (7) it would not make the home less attractive. This work shows that homeowners make retrofit decisions based on a portfolio of perceived attributes that depend on the type of retrofit under consideration. Although cost is important, other factors carry considerable weight in the decision as well. Further, findings suggest that study of one type of protective action (e.g., having an emergency kit) may not be generalizable to other actions (adding hurricane shutters) without considering these attributes.
\end{abstract}




\section{BIOGRAPHICAL SKETCH}

Yilin Zou is a Master of Science candidate from Cornell University, majoring in Transportation System Engineering. She was graduated from Beijing Jiaotong University with the Bachelor of transportation degree at 2017 as an extraordinary

graduate. At 2018, she got the Bachelor of Economics degree and began her graduate learning in transportation system engineering at Cornell University.

Other than academical focuses, Yilin is also interested in data analysis which plays an increasingly important role in many fields. She has an internship experience at Uber(China), combining data analysis applications and her transportation knowledge. She hopes to work in this industry in the future. 
I dedicate my thesis work to my parents, Lin Du and Doudou Zou.

本论文献给我的父母，杜林和邹斗斗。 


\section{ACKNOWLEDGMENTS}

I dedicate my thesis work to my parents. I'm grateful that they gave me opportunity to study abroad and pursue higher education. They are always supportive, without which I cannot make it today.

My thanks and appreciation to professor Linda K. Nozick, my advisor. I have got countless helps and valuable experience during my research work with her. Those would be still very helpful after my graduation.

I must acknowledge as well many colleagues, friends, and teachers who has helped me during my graduate study. Every course I took, every discussion with them, every talk means a lot and makes me who I am now. 


\section{TABLE OF CONTENTS}

Biographical Sketch..........................................................................................ii

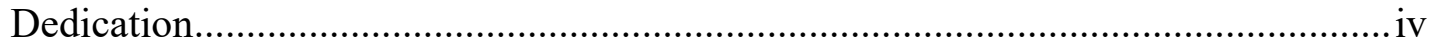

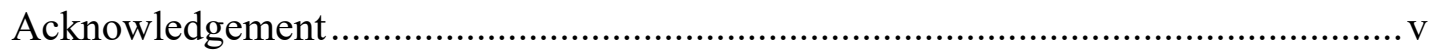

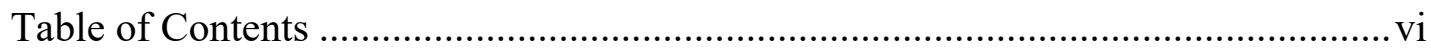

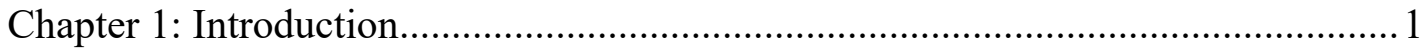

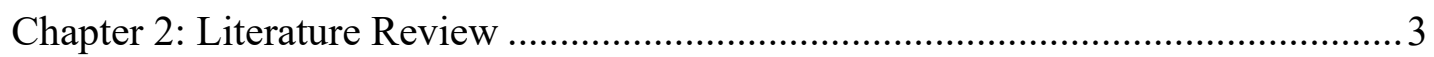

2.1 Perceived Protective Action Attributes....................................................... 3

2.2 Structural Retrofit as a Protective Action .................................................... 7

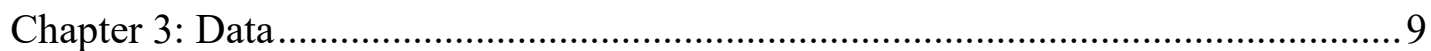

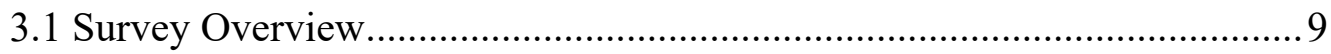

3.2 Response and Retrofit type variables....................................................... 10

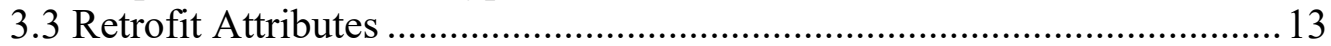

3.4 Control Variables .................................................................................. 14

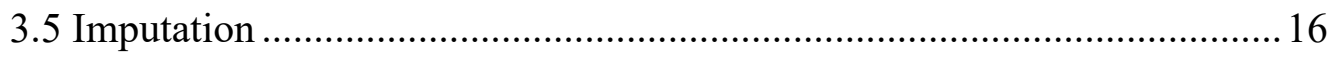

Chapter 4: Mixed Logit Model................................................................................. 18

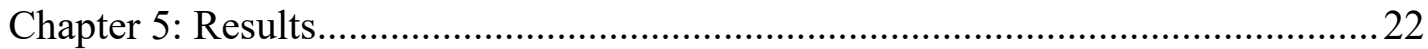

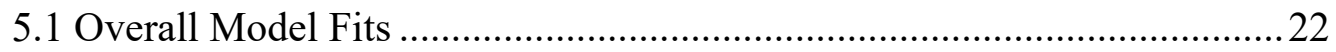

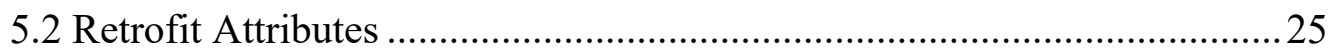

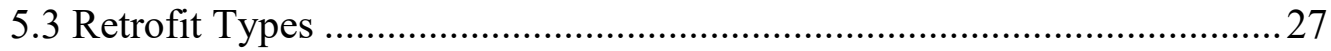

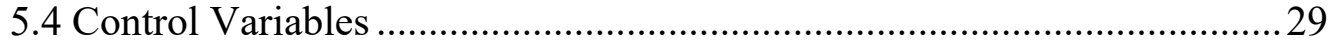

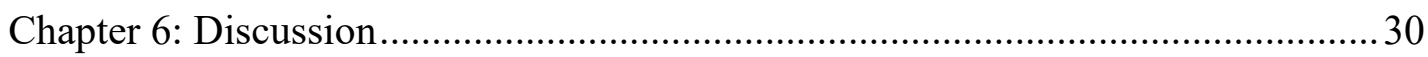




\section{CHAPTER 1}

\section{INTRODUCTION}

Recognizing the important role of individual households in managing risk from natural hazards, there has long been interest in understanding the process by which they make protective action decisions. The resulting literature has identified many social, economic, and other factors that likely influence household decisions to take actions to manage their risk (e,g, Lindell et al. 2009, Botzen and van den Bergh 2012, Botzen et al. 2009, CSSC 2009, Lindell and Perry 2000, Lindell and Whitney 2000, Grothmann and Reusswig 2006, Peacock 2003, McClelland et al. 1993, Langer 1975, Kunreuther et al. 1998): (1) psychological factors (e.g., risk perception, worry, hazard experience); (2) demographic factors (e.g., age, wealth); (3) location factors (e.g., hazard proximity, attributes of structure); (4) social influences (e.g., building codes, neighbors'

actions); (5) responsibility (e.g., expectation of disaster assistance); (6) emotion-focused coping strategies (e.g., wishful thinking, fatalism); and (7) cognitive heuristics and biases (e.g., illusion of control, short time horizon in evaluating consequences of actions). Nevertheless, there has been limited investigation of the role of perceived attributes of the protective actions themselves in influencing household protective action decisions (e.g., efficacy in protecting people and property, usefulness for other purposes, cost in dollars and time). This thesis work aims to add to that empirical literature by focusing on a type of protective action that has received little attention, hurricane-related structural retrofits, and on a range of attributes of those retrofit types that includes some not previously examined.

Using a combination of revealed preference (RP) and stated preference (SP) data from a mailed survey of homeowners in North Carolina, we fitted mixed logit models to predict the 
probability a household has or intends to structurally retrofit (strengthen) its home to mitigate hurricane wind and flood damage. Through questions about the likelihood of undertaking eight diverse types of retrofits and questions about the perceived attributes of those retrofits, we examine the relationship between the characteristics of the protective action and the probability of doing it. The eight retrofits are typical ways of mitigating hurricane wind damage (the first five) and flood damage (the last three)—wind resistant shingles, special foam adhesive under the roof, hurricane shutters, impact resistant windows, hurricane straps/ties, elevated appliances, water resistant siding, and home elevated on piles. The seven retrofit attributes considered are perceptions of cost, effort to install, understanding of how it works, value it adds to the home, efficacy in protecting lives, efficacy in protecting property, and effect on home attractiveness. Chapter 2 reviews the relevant literature on protective action. The data and mixed logit model formulation are described in Chapter 3 and 4, respectively. We present results in Chapter 5, and discuss implications for policy and future research in Chapter 6. 


\section{CHAPTER 2}

\section{LITERATURE REVIEW}

The protective action literature derives from multiple disciplines, including psychology, economics, decision sciences, and sociology. It includes analyses related to many hazards and diverse types of actions. The actions differ in when they are taken — long before an event (buying insurance, retrofitting) or shortly before in preparation of impact (positioning sandbags, evacuation). They differ in their intended effects - reducing damage, safeguarding life safety, improving the ability to pay for loss. In this review, we focus on studies that address the decision of an individual person or household to take protective action (also known as hazard adjustment or mitigation action), as opposed to community actions, such as building a seawall. We concentrate on research that explicitly considers attributes of the protective action, and that focuses on retrofit as a protective action.

\subsection{PERCEIVED PROTECTIVE ACTION ATTRIBUTES}

\subsubsection{THEORETICAL BASIS}

The idea that the attributes of protective actions may influence the likelihood of their adoption has appeared in different theories of protective action, including the Protective Action Decision Model (PADM), Protective Motivation Theory (PMT), and Theory of Planned Behavior (TPB). In PADM, perceptions of protective action attributes follow predecision processes which in turn follow warnings and environmental and social cues. Together with perceptions of the environmental threat and stakeholders, perceptions of protective action attributes then lead to protective action decisions and ultimately to action (Lindell and Perry 2012). PADM groups the attributes of protective actions (which it also calls hazard adjustments) 
into hazard-related (including efficacy in protecting people and property, usefulness for other purposes) and resource-related (including required cost, knowledge, skill, time, effort, and cooperation with others) (Lindell and Perry 2012, Lindell and Whitney 2000, Lindell and Prater 2002, Lindell et al. 2009, Terpstra and Lindell 2013). In PMT, threat appraisal and coping appraisal combine to determine protection motivation, which is followed by a response (Floyd et al. 2000). Perceived attributes of protective actions are incorporated within the coping appraisal process, which includes response efficacy (effectiveness of risk mitigation behaviors), selfefficacy (individual's perceived ability to implement risk mitigation), and response costs (financial, time, and other related costs associated with risk mitigation). Lindell and Perry (2012) explain that PADM's hazard-related attributes are similar to but broader than, PMT's response efficacy; and that PADM's resource-related attributes differ from PMT's self-efficacy because the former are attributes of the protective action while the latter are attributes of the person. In TPB, three components influence an individual's intention to complete a behavior (protective action in this case) - attitude toward the behavior, subjective norm, and perceived behavioral control (Ajzen 1991). What we refer to as perceived attributes of the protective action could appear in the theory in the attitude toward the behavior factor. While the analysis in this thesis is informed by all of these theories, it is not designed around any single one. Instead its central contribution is expanding the measurement of protective action attributes in a way that could be applied to any of these theoretical models.

\subsubsection{EMPIRICAL EVIDENCE}

These theories have informed empirical studies of the influence of protective action attributes in protective action decision-making. With PADM as a theoretical basis, a number of studies have focused explicitly on the effect of protective action attributes (Terpstra and Lindell 
2013, Lindell and Perry 2012, Lindell et al. 2009, Lindell and Prater 2002, Lindell and Whitney 2000). Lindell et al. (2009), Lindell and Prater (2002), and Lindell and Whitney (2000) all address the earthquake hazard and a set of 12 or 16 possible protective actions that are mostly related to preparedness (e.g., have a radio with spare batteries, have a first aid kit) plus buying earthquake insurance and securing water heaters and other contents. Terpstra and Lindell (2013) is similar, but applied to flooding and considering six possible actions (emergency kit, information, household plan, plan with others, sandbags, flood insurance). In each study, respondents rated each action according to the hazard- and resource-related protective action attributes from PADM. This works suggests overall that the hazard-related attributes are significantly correlated with adoption intention and actual adjustment, but have found little evidence that resource-related attributes are correlated with the same (Lindell and Perry 2012).

Grothman and Reusswig (2006) used PMT to study household protective actions for flood (seeking information, moving contents to upper floors, buying flood protective devices like pumps, and structural measures like putting heating in upper floors). They found that a single overall measure of coping appraisal was statistically significant in predicting all four actions. Focused on building fires, Liu and Jiao (2018) also employed PMT and found that response efficacy was significant in influencing structural measures (e.g., using fire-resistant roofing) and fire insurance purchase, and response cost was significant for maintenance and caution activities (e.g., removing vegetation near house).

Drawing on PADM, PMT, and regulatory focus theory, de Boer et al. (2015) examined perceptions of four possible protective actions for flood (emergency kit, information seeking, buying sandbags, and tiling the floor) according to five attributes (effectiveness for safety, effectiveness for damage reduction, efficiency for flood control, difficulty applying, difficulty 
judging usefulness, necessity). Daellenbach et al. (2018) used TPB to investigate people's general intent to be prepared for disasters. They considered five possible barriers to disaster preparation (i.e., cost, knowledge or skill required, time required, other things to think about, and need for cooperation with others), which were combined into a single measure and used with intent to prepare to cluster segments of the population.

McClure et al. (2014) examined three classes of earthquake-related protective actions, with four specific actions each—supporting survival immediately after, mitigating building damage, and mitigating contents damage. They examined the relationship between cost and the actions, and for those respondents who did not complete the action, they asked why, offering eight reasons, including four related to attributes of the actions (cost, too busy, only useful for earthquakes, would not make much difference). They found takeup rates varied widely across action types, cost was significant only for four of the mitigation actions, and the other three attributes were among the lower ranked reasons for not undertaking actions.

Some previous work on extreme event insurance highlighted cost (i.e., premiums, deductibles) and difficulty determining availability and details of policies (which may be interpreted as required effort) as attributes affecting takeup rates (e.g., Brody et al. 2017, Savitt 2017).

Overall, the literature is limited in extent; in the types of hazards, actions, and attributes investigated; and in the consistency of how they are measured. Taken in sum, the record offers mixed evidence for a number of measures, but most often suggests that perceived cost, ability to protect property, and ability to protect life are important attributes of a protective action that influence their takeup rates. In this study, we adopt the protective action attributes cost, effort required, life protection, and property protection in order to replicate these measures most often 
found in PADM and PMT analyses. We also consider three additional attributes — understanding of how the action works, added value to the home, and effect on home's attractiveness - that have particular relevance for hurricane-related structural retrofits, the focus herein. Specifically, in this thesis, we hypothesize that a higher probability of undertaking a retrofit is associated with homeowner beliefs that: (1) the retrofit cost is not too high, (2) the installation does not require too much effort, (3) they understand how it works, (4) it would add to home value, (5) it would protect lives, (6) it would protect property, and (7) it would not make the home less attractive.

\subsection{STRUCTURAL RETROFIT AS A PROTECTIVE ACTION}

Among possible protective actions a homeowner could take to minimize disaster loss, the decision to structurally retrofit her home has received relatively little attention in the literature. Focusing on wind mitigation, Peacock (2003) estimated the extent of hurricane shutter usage and envelope coverage as functions of household characteristics. In examining the effect of incentives on household mitigation, Ge et al. (2011) studied the decision to install hurricane shutters. Carson et al. (2013) used records of inspections, grant applications, and mitigation grants from the My Safe Florida Home program in Florida to investigate the probability of mitigating and the amount spent on mitigation. Mitigation was treated as a binary variable with a value of one if the respondent undertook at least one of the wind damage reduction strategies

allowed under the program. Studying the combination of wind mitigation and insurance purchase decisions, Petrolia et al. (2015) considered the following wind retrofits and coded the response variable as number of mitigation activities from 0 to $5+$ : storm shutters, roof anchors, reinforced doors, wind-resistant glass, wind-resistant shingles, and hurricane ties.

In flood-related research, Grothmann and Reusswig (2006) used survey data in Germany to study household decisions to purchase flood mitigation devices (e.g., pumps) and undertake 
structural mitigation, such as elevating heating equipment. Kreibich et al. (2005) and Thieken et al. (2006) analyzed mitigation by households affected by the 2002 Elbe floods in Germany. They considered building elevation, shielding with water barriers, waterproof sealing, strengthening the building foundation, building use adaptation, adaptation of interior fittings, and safeguarding of hazardous substances. Botzen et al. (2013), asked about willingness to elevate a home to reduce flood risk. Poussin et al. $(2014,2015)$ used data from France to examine the number of flood mitigation measures in the house and the intent to do them in the future. They considered 24 measures grouped into fourteen structural measures (e.g., raising ground floor, strengthening foundation), five avoidance measures (e.g., raising appliances), and five emergency preparedness measures (e.g., owning sandbags, having emergency plan). Using data from across Germany, Osberghaus (2015) examined the decision to do (or intent to do) any of six flood mitigation measures - moving assets to higher floors; water barriers at basement openings; back flow flap; water-resistant exterior paint coat, interior paint coat, or floor. In examining the effect of financial incentives on the hurricane retrofit decision, Jasour et al. (2018) and Chiew et al. (in review) separately modeled homeowner decisions about retrofits aimed at addressing four types of hurricane damage — wind damage to the roof, openings (windows, doors), and roof-to-wall connection, and flood damage.

Like these studies, the research presented herein focuses on structural retrofits. We consider a larger and more varied set of typical retrofit types, however, representing a range of values for the attributes of interest (e.g., a range of costs, effectiveness for reducing life loss). This study also adds to this literature by focusing on the perceived attributes of the different retrofits and their influence on the decision to undertake them. 


\section{CHAPTER 3}

\section{DATA}

\subsection{SUVEY OVERVIEW}

A mail survey was designed to collect information about household-level hurricane mitigation decisions. It took approximately 20 minutes to complete and included questions on risk perception and prior hurricane experience, past and hypothetical future decisions about retrofitting the home or accepting an acquisition offer, and sociodemographic factors. Screening questions ensured the respondent was eligible to participate, i.e., at least 18 years old, owned the property the survey was mailed to, and contributed to the household's home improvement decision-making process.

The survey sample was purchased from Genesys, which utilizes the United States Postal Service's address database system to select random addresses for research purposes (Marketing Systems Group 2018). The sample contained 2500 randomly selected addresses, screened to include only single-family, owner-occupied properties in the Eastern half of North Carolina, from the capital of Raleigh to the coast. The study area was chosen because it has a long history of damaging hurricanes and has been active in encouraging homeowner hurricane mitigation efforts.

The survey was mailed in January 2017. To maximize response rates, Dillman (2007) procedures were followed, including development of a respondent-friendly survey, four contacts through first-class mail, stamped return envelopes, personalization of correspondence, and \$1 prepaid financial incentives. The final dataset analyzed in this study includes 234 completed surveys. Based on American Association for Public Opinion Research response rate definitions 
(AAPOR 2019), the minimum response rate, comparing number of completed surveys to eligible households in the sample, is $10 \%$, and the cooperation rate, comparing completed surveys to households with confirmed contact, is $90 \%$. This suggests that an important factor in reducing the number of responses was the well-known problem of non-contact.

The sample is slightly older and Whiter than the population of homeowners in the eastern half of North Carolina. Since the average age of first-time homebuyers in 2017 was 32 years (Ramirez 2017), we assume homeowners include only people $30+$ years. The average age in our sample was then 58 years, compared to 54 years in the population. The sample was $85 \%$ White vs. $67 \%$ for the population.

\subsection{RESPONSE AND RETROFIT TYPE VARIABLES}

The survey elicited both revealed preference (RP) and stated preference (SP) data for the binary response variable, $y$, Retrofit (1) or No retrofit (0). Whereas RP data relate to actual past choices in real world situations, SP data describe intentions in hypothetical future situations. RP data are thought to be more reliable because they reflect actual choices, but they are limited by the choice situations that have existed in the past, so they are not available for some situations and often include limited variation in attribute values (Train 2009). Questions to elicit SP data can be designed to address new or hypothetical choices and to contain more attribute variation, but may be subject to bias if what people say they will do differs from what they actually will do. Combining the two data types allows us to leverage the strengths of each. The coefficients that represent the relative importance of attributes are estimated using both types of data, reflecting the amount of variation each type includes. The alternative-specific constants (ASCs), which represent the average probability of retrofitting are estimated separately for RP and SP data. By using the RP ASCs, we avoid the bias associated with the SP data (Section 4). 
The RP question asked, for each of eight home features, "Please mark the box that best describes if your current home has each feature." For each home feature, the responses "My home does not have this feature or I don't know if it does" and "My home has this feature and it was not important to me when I bought it" were both coded as No. The responses "My home has this feature and it was important to me when I bought it" and "My home has this feature and I added it after I bought the home" were coded as Yes. The eight features were (1) Wind resistant shingles, (2) Special foam adhesive under the roof, (3) Hurricane shutters, (4) Impact resistant windows, (5) Hurricane straps/ties, (6) Elevated appliances, (7) Water resistant siding, and (8) Home elevated on piles. The first five home features help determine a home's vulnerability to wind damage and adding them are typical ways to retrofit a home to reduce hurricane-induced wind damage. They were defined to be compatible with those recommended in the IBHS FORTIFIED Home program (IBHS 2017). The last three home features, adopted from Taggart and van de Lindt (2009), help determine a home's vulnerability to flood damage and adding them are typical ways to retrofit a home to reduce hurricane-induced flood damage.

Table 1. Number of respondents associated with each level for response $(y)$, retrofit type $\left(z_{t y p e}\right)$, and retrofit attribute variables ( $\left.x_{\text {cost }}-x_{\text {atract }}\right)$

\begin{tabular}{|c|c|c|c|c|}
\hline \multicolumn{2}{|r|}{ Variable } & Levels & \multicolumn{2}{|c|}{$\begin{array}{l}\text { Number of } \\
\text { respondents }\end{array}$} \\
\hline \multirow{3}{*}{$y$} & \multirow{3}{*}{ Retrofit } & & $\mathrm{RP}$ & SP \\
\hline & & $0:$ No retrofit & 1578 & 936 \\
\hline & & 1: Retrofit & 166 & 383 \\
\hline \multirow{9}{*}{$z_{\text {type }}$} & \multirow{9}{*}{ Retrofit type } & & $\mathrm{RP}$ & SP \\
\hline & & 0 : Wind resistant shingles & 222 & 158 \\
\hline & & 1: Special foam adhesive under the roof & 219 & 150 \\
\hline & & 2: Hurricane shutters & 219 & 163 \\
\hline & & 3: Impact resistant windows & 216 & 175 \\
\hline & & 4: Hurricane straps/ties & 217 & 166 \\
\hline & & 5: Elevated appliances & 218 & 170 \\
\hline & & 6: Water resistant siding & 218 & 166 \\
\hline & & 7: Home elevated on piles & 215 & 171 \\
\hline \multirow[b]{2}{*}{$x_{\text {cost }}$} & \multirow{2}{*}{ Cost } & 0 : Think cost of retrofit is too high & \multicolumn{2}{|c|}{906} \\
\hline & & 1: Do not think cost of retrofit is too high & \multicolumn{2}{|c|}{636} \\
\hline$x_{\text {effort }}$ & Effort & 0: Think retrofit requires too much effort to install & \multicolumn{2}{|c|}{780} \\
\hline
\end{tabular}




\begin{tabular}{lllc}
\hline & & 1: Do not think retrofit requires too much effort to install & 697 \\
\hline \multirow{2}{*}{$x_{\text {under }}$} & \multirow{2}{*}{ Understanding } & 0: Do not understand how retrofit works & 523 \\
& & 1: Understand how retrofit works & 1084 \\
\hline \multirow{2}{*}{$x_{\text {value }}$} & \multirow{2}{*}{ Value added } & 0: Do not think retrofit would add value if sell home & 772 \\
& & 1: Think retrofit would add value if sell home & 748 \\
\hline \multirow{2}{*}{$x_{\text {lives }}$} & \multirow{2}{*}{ Life protection } & 0: Do not think retrofit would protect lives & 762 \\
& & 1: Think retrofit would protect lives & 784 \\
\hline \multirow{2}{*}{$x_{\text {prop }}$} & \multirow{2}{*}{ Property protection } & 0: Do not think retrofit would protect property & 496 \\
& & 1: Think retrofit would protect property & 1075 \\
\hline \multirow{2}{*}{$x_{\text {attract }}$} & \multirow{2}{*}{ Attractiveness } & 0: Think retrofit would make home less attractive & 382 \\
& & 1: Do not think retrofit would make home less attractive & 1144 \\
\hline
\end{tabular}

${ }^{\text {a }}$ All retrofit attribute variables, $\vec{x}$, were coded so that in each case zero refers to a negative sentiment about the retrofit and one refers to a positive sentiment about the retrofit.

To elicit the SP response variable values, the survey asked "For this question, we would like you to imagine that you moved to a new home that did not have any of the following features. With that assumption, tell us if you would add each feature within five years." The question was asked for the same eight home features, with possible responses of Yes, No, or Not sure. Responses of Not Sure were considered missing data. For each respondent, therefore, we collected up to 16 observations, response from RP and SP questions for each of the eight home features (retrofit types). A total of 3063 observations were collected from the 234 respondents (Table 1).

The Retrofit type variable, $z_{\text {type }}$, is an indicator variable, implemented using seven binary dummy variables, that identifies which of the eight home features the response variable for a particular observation is associated with. There would be 234 responses for each data type (RP and SP) and each home feature, except that there were some missing responses and Not sure was considered missing for the SP question (Table 1).

Table 2. Percentage of respondents who retrofit and who think positively about perceived attributes, by retrofit type

\begin{tabular}{c|rc|ccccccc}
\hline & \multicolumn{3}{|c|}{$\begin{array}{c}\text { \% people } \\
\text { who retrofit }\end{array}$} & \multicolumn{6}{c}{ \% people who think positively about perceived attribute for } \\
ench retrofit type $\left(x_{k}=1\right)$
\end{tabular}




\begin{tabular}{l|rr|rrrrrrr}
\multicolumn{1}{l|}{ under roof } & & & & & & & & & \\
Hurricane shutters & 2.7 & 30.7 & 37.4 & 52.4 & 82.2 & 51.8 & 69.5 & 76.5 & 68.6 \\
Impact resist. windows & 14.8 & 50.3 & 32.3 & 45.7 & 81.4 & 70.3 & 86.0 & 88.1 & 91.8 \\
Hurricane straps/ties & 14.7 & 27.7 & 57.2 & 55.9 & 66.7 & 43.8 & 64.9 & 67.4 & 66.0 \\
Elevated appliances & 3.7 & 10.0 & 49.2 & 52.2 & 66.2 & 25.7 & 27.9 & 47.6 & 61.3 \\
Water resistant siding & 14.7 & 38.0 & 41.8 & 46.4 & 70.4 & 54.6 & 35.6 & 68.6 & 85.7 \\
Home elevated on piles & 4.7 & 8.2 & 25.8 & 21.0 & 75.1 & 27.8 & 46.6 & 48.0 & 41.7 \\
\hline All types & 9.5 & 29.0 & 41.2 & 47.2 & 67.5 & 49.1 & 50.7 & 68.4 & 75.0 \\
\hline
\end{tabular}

Table 2, which summarizes the responses by data type (RP vs. SP) and retrofit type, highlights two important points about the data. First, the percentage of people who say they intend to retrofit ( $29 \%$, SP response) is three times higher than the percentage who say they have (9.5\%, RP response). The model specification is intended to address this difference-specifically using the variability in the SP data to help estimate the coefficients, but using the RP data to estimate the constants that root the overall percentage of retrofit in actual past behavior (Section 4). Second, the percentage of people who retrofit varies a lot by retrofit type, from $2 \%$ to $16 \%$ in the RP data, and from $8 \%$ to $50 \%$ in the SP data. This raw data suggests the retrofit types do differ in some way that affects individual's likelihood to do them. Identifying the attributes by which they differ is a key aim of this study.

\subsection{RETROFIT ATTRIBUTES}

For each of the eight home features, respondents were asked "Please tell us if you think the following statements are true for each feature." They then responded Yes or No to the following seven statements: (1) The cost of this feature is too high, $x_{\text {cost }}$; (2) This feature requires too much effort to install, $x_{\text {effort }}$; (3) I understand how this feature works, $x_{\text {under }}$; (4) This feature would add value if I sell my home, $x_{\text {value }}$; (5) This feature would protect lives, $x_{\text {lives }}$; (6) This feature would protect my property, $x_{\text {prop}}$; and (7) Adding this feature would make my home less attractive, $x_{\text {attract }}$. For consistency, the resulting variables were coded so that in each case zero refers to a negative sentiment about the retrofit (e.g., the cost is too high, it would not protect 
property) and one refers to a positive sentiment about the retrofit (Table 1). Note that these variables all represent perceived attributes of the retrofits. We made no attempt to provide actual costs or measures of the effort required, for example, because those "objective" measures vary widely, and in any case, homeowner retrofit decisions are based on their perceptions. There is a lot of variability in retrofit attribute perceptions (Table 2). Perceptions of cost $\left(x_{\cos t}\right)$, effort $\left(x_{\text {effort }}\right)$, value added $\left(x_{\text {value }}\right)$, and protection of lives $\left(x_{\text {lives }}\right)$, which are approximately $45 \%$ positive across retrofit types, tend to be more negative than perceptions of understanding $\left(x_{\text {under }}\right)$, protection of property $\left(x_{\text {prop }}\right)$, and attractiveness $\left(x_{\text {attract }}\right)$, which are approximately $70 \%$ positive across retrofit types (Table 2). The data also suggest that the perceptions vary across retrofit types, with elevating the home on piles for example, being well understood but perceived as relatively high cost, requiring a lot of effort, and not adding value to the home, but special foam adhesive under the roof being not well understood but attractive (Table 2).

\subsection{CONTROL VARIABLES}

Table 3. Descriptive statistics for continuous control variables

\begin{tabular}{llcrc}
\hline & \multicolumn{1}{c}{ Variable } & $\begin{array}{c}\text { Number of } \\
\text { respondents }\end{array}$ & Mean & $\begin{array}{c}\text { Standard } \\
\text { deviation }\end{array}$ \\
\hline$w_{\text {dist }}$ & Distance to coastline $(\mathrm{km})$ & 229 & 98.7 & 69.9 \\
$w_{n w}$ & Net worth $(\$ 1,000 \mathrm{~s})$ & 190 & 303.8 & 226.8 \\
\hline
\end{tabular}

${ }^{1}$ Net worth was asked as an interval variable but was coded as a continuous variable with the values in parentheses for each interval: less than $\$ 50 \mathrm{k}(\$ 25 \mathrm{k}), \$ 50 \mathrm{k}-\$ 100 \mathrm{k}(\$ 75 \mathrm{k}), \$ 100 \mathrm{k}-\$ 150 \mathrm{k}(\$ 125 \mathrm{k}), \$ 150 \mathrm{k}-\$ 200 \mathrm{k}(\$ 175 \mathrm{k}), \$ 200 \mathrm{k}-$ $\$ 300 \mathrm{k}(\$ 250 \mathrm{k}), \$ 300 \mathrm{k}-\$ 400 \mathrm{k}(\$ 350 \mathrm{k}), \$ 400 \mathrm{k}-\$ 500 \mathrm{k}$ (\$450k), and more than $\$ 500 \mathrm{k}(\$ 600 \mathrm{k})$.

Table 4. Number of respondents associated with each level for categorical control variables

\begin{tabular}{|c|c|c|c|}
\hline & Variable & Levels & $\begin{array}{l}\text { Number of } \\
\text { respondents }\end{array}$ \\
\hline \multirow[b]{2}{*}{$w_{f p}$} & \multirow{2}{*}{$\begin{array}{l}\text { Location in } \\
\text { floodplain }\end{array}$} & 0: Not in floodplain & 205 \\
\hline & & 1: In floodplain & 24 \\
\hline \multirow{2}{*}{$w_{\text {perdis }}$} & \multirow{2}{*}{$\begin{array}{l}\text { Perceived } \\
\text { disruption }\end{array}$} & 0: Hurricane unlikely to cause significant disruption to your life & 151 \\
\hline & & 1: Hurricane likely to cause significant disruption to your life & 81 \\
\hline \multirow[b]{2}{*}{$w_{\text {self }}$} & \multirow{2}{*}{ Self-efficacy } & 0: Do not believe personal actions matter in determining damage & 89 \\
\hline & & 1: Believe personal actions matter in determining damage & 145 \\
\hline$w_{\text {tenure }}$ & Future tenure & 0: Forever & 48 \\
\hline
\end{tabular}




\begin{tabular}{|c|c|c|c|}
\hline & & 1: Less than forever & 170 \\
\hline \multirow{3}{*}{$w_{m g}$} & \multirow{3}{*}{$\begin{array}{l}\text { Marital status } \\
\text { and gender }\end{array}$} & 0: Single female & 47 \\
\hline & & 1: Single male & 25 \\
\hline & & 2: Married & 153 \\
\hline \multirow[b]{2}{*}{$w_{\text {race }}$} & \multirow{2}{*}{ Race } & 0: White & 187 \\
\hline & & 1: Not white & 34 \\
\hline \multirow{3}{*}{ Wemploy } & \multirow{3}{*}{$\begin{array}{l}\text { Employment } \\
\text { status }\end{array}$} & 0: Employed & 107 \\
\hline & & 1: Unemployed & 14 \\
\hline & & 2: Retired/Unable to work & 105 \\
\hline \multirow{2}{*}{$W_{e d u c}$} & \multirow{2}{*}{ Education } & $0: \geq 4$ years beyond high school & 134 \\
\hline & & 1: $<4$ years beyond high school & 91 \\
\hline
\end{tabular}

Several control variables identified from the literature were included as well (Jasour et al. 2018). Tables 3 and 4 provide the descriptive statistics for the continuous and categorical control variables, respectively. Hypothesizing that homes with higher estimated risk are more likely to be retrofitted (Ge et al. 2011, Jasour et al. 2018), we included two variables to represent the model-estimated risk, straight-line nearest Distance to coastline in kilometers $\left(w_{\text {dist }}\right)$ and Location in a floodplain $\left(w_{f p}\right)$, both of which were computed in a geographic information system (GIS) based on the geocoded mailing address. The latter was determined by overlaying households on 100-year FEMA flood insurance rate maps.

Risk perception, self-efficacy, and other psychological factors have also been considered possible factors influencing homeowner protective action decisions (e.g., Bubeck et al. 2012, Grothmann and Reusswig 2006, Lindell and Hwang 2008, Ge et al. 2011). In this study, risk perception was represented with the variable Perceived disruption ( $w_{\text {perdis }}$ ), which was obtained by asking "If a hurricane affects North Carolina, how likely is it to cause significant disruption to your life?" Responses on a five-point Likert scale (Very Unlikely, Unlikely, Not Sure, Likely, and Very Likely) were collapsed into a binary variable with the first three levels coded as Unlikely, and the last two coded as Likely. The respondent's sense of self-efficacy was captured with the question "Do you believe that your actions matter in determining how much a hurricane will 
damage your home?” Responses on a five-point Likert scale (Strongly disagree, Disagree, Neutral, Agree, and Strongly agree) were again collapsed into a binary variable with the first three responses coded as Disagree and the last two as Agree.

The variable Net worth $\left(w_{n w}\right)$ was included to indicate the homeowner's financial ability to pay for a retrofit. Peacock (2003), Grothmann and Reusswig (2006), Osberghaus (2015), and Ge et al. (2011) all report evidence that the related variable of higher income is associated with more mitigation. In Petrolia et al. (2015) and Poussin et al. (2014), however, income was not a significant predictor of mitigation. In asking respondents to define their net worth, the survey question clarified that "By net worth, we mean the total value of cash, checking, savings, investments, and property of your household minus any loans."

Since the benefits of a home retrofit are only reaped at some point in the future if and when a hurricane occurs and damage is avoided, we hypothesized that a longer expected Future tenure $\left(w_{\text {tenure }}\right)$ in the home is associated with a higher probability of retrofit. Of the 218 responses to the question "How many more years do you expect to own your home?", 48 (22\%) people said Forever, so we coded the variable Future tenure ( $w_{\text {tenure }}$ ) as binary with values Forever (0) and Less than forever (1). Finally, sociodemographic variables Marital status and gender ( $\left.w_{m g}\right)$, Race ( $\left.w_{\text {race }}\right)$, Employment status ( $w_{\text {emply }}$ ), and Education ( $\left.w_{\text {educ }}\right)$ were also included as control variables.

\subsection{IMPUTATION}

The dataset included some missing values in a patchwork pattern. Since pairwise or listwise data deletion can lead to loss of many observations and potentially biased estimation and interpretation (Harrell 2015), we used multiple imputation, implemented with the package \{mice\} in R, to address the issue (van Buuren and Groothuis-Oudshoorn 2010, van Buuren 2018). 
Observations with missing response values were omitted, but all other missing values were imputed based on their data types, logistic regression for binary variables and predictive mean matching for the other variables. As recommended in Harrell (2015) and White et al. (2011), all variables were used as predictors. Repeating the process ten times resulted in ten complete datasets. A comparison of the distributions of observed and imputed data for each variable confirmed they were adequately similar. Models were estimated separately for each dataset, and results were then combined using Rubin's rules to get a final pooled estimation result (van Buuren 2018, White et al. 2011). 


\section{CHAPTER 4}

\section{MIXED LOGIT MODEL}

The data used in this analysis has a few important features: (1) the response variable is a binary choice (No retrofit or Retrofit), (2) it includes both RP and SP data and thus may have an RP-SP scale difference and state dependence, and (3) it is panel data since each respondent was asked both RP and SP for eight different retrofit types (i.e., 16 choice situations). Mixed logit models were employed because of their ability to address these features (Bhat and Castelar 2002). First, when combining RP and SP data it is necessary to allow the scale for the RP responses and the scale for the SP responses to differ because it is possible that the variance of the unobserved factors in the two settings are not the same. In the mixed logit model, this is achieved by normalizing the scale parameter for one type of data to one, and defining the scale parameter for the other type of data relative to that of the first type (Train 2009, Hensher et al. 2008). Second, state dependence captures the idea that the actual RP choices may influence the SP choices. In this study, someone who has retrofit in the past may be more or less likely to say they intend to in the future. Finally, since the data is panel data, with each respondent providing answers for up to eight RP and eight SP questions, we recognize that an individual's responses across multiple choice situations may be affected by common unobserved attributes of the individual.

To address these issues, we adopted the Bhat and Castelar (2002) unified framework (with $\mu=0$ to omit the correlation across unobserved components of the alternatives since we have only two alternatives). In each choice situation $t$, each individual $i$ is assumed to choose the alternative $j$ that maximizes her utility, $U_{i j t}$, defined as:

$$
U_{i j t}=\alpha_{j}+\vec{\beta}^{T} \vec{x}_{i t}+\vec{\gamma}^{T} \vec{w}_{i}+\vec{\delta}^{T} \vec{z}_{t}+\varphi_{i}\left[\left(1-\kappa_{R P, i t}\right)\left(\sum_{s=1}^{T_{i}} \kappa_{R P, i s} Y_{i j s}\right)\right]+\varepsilon_{i j t} \quad \text { for } j=\text { Retrofit }
$$




$$
U_{i j t}=\varphi_{i}\left[\left(1-\kappa_{R P, i t}\right)\left(\sum_{s=1}^{T_{i}} \kappa_{R P, i s} Y_{i j s}\right)\right]+\varepsilon_{i j t} \quad \text { for } j=\text { No retrofit }(1 \mathrm{~b})
$$

The $\alpha_{j}$ is the alternative-specific constant (ASC) for alternative $j$. The variables $\vec{x}_{i t}, \vec{w}_{i}$, and $\vec{z}_{t}$ are vectors of observed covariates relating to the retrofit attributes (Section 3.3), individualspecific control variables (Section 3.4), and retrofit types (Section 3.2), respectively, for individual $i$ and choice situation $t$. The control variables vary across individuals but not alternatives or choice situations, and the retrofit type variables vary across choice situations but not individuals. The coefficients $\vec{\beta}, \vec{\gamma}$, and $\vec{\delta}$ are the corresponding vectors of coefficients for retrofit attributes, control variables, and retrofit types. The value of the ASC can be considered the average effect of all factors not in the model on the utility of retrofitting relative to not retrofitting. Similarly, the values of $\vec{\gamma}$ can be considered the effect of each associated $\vec{w}_{i}$ variable on the utility of retrofitting relative to not retrofitting.

The individual-specific state-dependence effect, $\varphi_{i}$, represents the effect of the RP choice on the utility of the SP choice situation; $\kappa_{R P, i t}$ is a dummy variable that is one if choice situation $t$ for individual $i$ corresponds to an RP choice and zero otherwise; $Y_{i j s}$ is a binary value that is one if individual $i$ chooses alternative $j$ in the $s^{\text {th }}$ choice situation and zero otherwise; and $T_{i}$ is the total number of observed choice situations for individual $i$. For each RP choice situation, since $\kappa_{R P, i t}=1$, the entire fifth term in Equation 1a and first term in Equation $1 \mathrm{~b}$ reduce to zero. In addition, the summation is one if individual $i$ chose alternative $j$ in the RP situation and zero otherwise. Thus, the term as a whole has the effect of adding $\varphi_{i}$ to the utility equation for alternative $j$ in each SP choice situation if individual $i$ chose $j$ in the RP choice situation; it has no effect on any other utilities. Finally, $\varepsilon_{i j t}$ is an unobserved random term that captures omitted variables. We assume $\varepsilon_{i j t}$ are independently and identically extreme value I distributed across 
alternatives and individuals for each choice situation, and independently (but not identically) distributed across choice situations (Bhat and Castelar 2002).

As noted, to accommodate potentially different scales for the SP and RP data, we normalize the scale parameter for the RP data to one, and define the scale parameter for the SP data relative to that of the RP data (Train 2009, Hensher et al. 2008). Thus, the scale parameter for individual $i$ in choice situation $t, \lambda_{i t}$, is defined as:

$$
\lambda_{i t}=\left[\left(1-\kappa_{R P, i t}\right) \lambda\right]+\kappa_{R P, i t}
$$

where $\lambda$ is the SP scale relative to RP. We estimated $\lambda$ as described in Hensher et al. (2008) by introducing an ASC into the SP data that has a zero mean. According to the extreme value Type I distribution then, $\lambda=\pi /(\sigma \sqrt{6})$, where $\sigma$ is the estimated standard deviation of the ASC of the SP choice (Train 2009, Hensher et al. 2008). Thus, the retrofit ASC estimated using the SP data was not available, and we used the retrofit ASC estimated with the RP data, which we expect is more reliable anyway. Note that we explored the possibility of including unobserved preference heterogeneity (i.e., unobserved (to the analyst) differences across individuals in the intrinsic preference for a choice alternative) by making the ASC individual-specific but in a preliminary analysis the standard deviation was not statistically significant ( $p$-value $=0.99$ ) and thus, given the limited sample size, we omitted it.

With the utility functions defined as in Equation 1, the probabilities that in choice situation $t$ individual $i$ chooses alternative $j=0=$ No retrofit or $j=1=$ Retrofit are:

$$
\begin{aligned}
& \operatorname{Pr}\left(y_{i t}=0\right)=\frac{\exp \left(U_{i t, j=0}\right)}{\exp \left(U_{i t, j=0}\right)+\exp \left(U_{i t, j=1}\right)} \\
& \operatorname{Pr}\left(y_{i t}=1\right)=\frac{\exp \left(U_{i t, j=1}\right)}{\exp \left(U_{i t, j=0}\right)+\exp \left(U_{i t, j=1}\right)}
\end{aligned}
$$

The modeling was implemented using the gmnl package in R (Sarrias and Daziano 2017). 


\section{CHAPTER 5}

\section{RESULTS}

\subsection{OVERALL MODEL FIT}

Table 5. Comparison of alternative model specifications

\begin{tabular}{|c|c|c|c|c|c|c|c|c|}
\hline \multirow[b]{2}{*}{ Attribute } & \multicolumn{2}{|c|}{$\begin{array}{c}\text { Model } 1 \\
\text { Base model }\end{array}$} & \multicolumn{2}{|c|}{$\begin{array}{c}\text { Model } 2 \\
\text { No retrofit type }\end{array}$} & \multicolumn{2}{|c|}{$\begin{array}{c}\text { Model } 3 \\
\text { No insignificant control variables }\end{array}$} & \multicolumn{2}{|c|}{$\begin{array}{c}\text { Model } 4 \\
\text { No retrofit type, } \\
\text { no insig control variables }\end{array}$} \\
\hline & Coeff & p-value ${ }^{\mathrm{a}}$ & Coeff & p-value ${ }^{\mathrm{a}}$ & Coeff & p-value ${ }^{a}$ & Coeff & p-value \\
\hline \multicolumn{9}{|l|}{ Alternative-specific constant } \\
\hline $\mathrm{RP} \mathrm{ASC}, \alpha_{j}$ & 4.340 & $0.000^{* * *}$ & -2.648 & $0.002^{* *}$ & -3.935 & $0.000^{* * *}$ & -2.307 & $0.000^{* * *}$ \\
\hline \multicolumn{9}{|l|}{ Perceived retrofit attribute variables ${ }^{b}$} \\
\hline Cost, $x_{\text {cost }}$ & 0.903 & $0.001^{* * *}$ & 0.701 & $0.004^{* *}$ & 0.857 & $0.001^{* *}$ & 0.692 & $0.008^{* *}$ \\
\hline Effort, $x_{\text {effort }}$ & 0.355 & 0.122 & 0.460 & $0.041^{*}$ & 0.376 & 0.089 & 0.455 & $0.043^{*}$ \\
\hline Understand, $x_{\text {under }}$ & 0.722 & $0.007^{* *}$ & 0.599 & $0.015^{*}$ & 0.725 & $0.007^{* *}$ & 0.599 & $0.020^{*}$ \\
\hline Value, $x_{\text {value }}$ & 0.686 & $0.003^{* *}$ & 1.018 & $0.000^{* * *}$ & 0.727 & $0.002^{* *}$ & 1.034 & $0.000^{* * *}$ \\
\hline Lives, $x_{\text {lives }}$ & 0.796 & $0.001^{* * *}$ & 0.698 & $0.001^{* *}$ & 0.809 & $0.001^{* * *}$ & 0.707 & $0.003^{* *}$ \\
\hline Property, $x_{\text {prop }}$ & 1.105 & $0.003^{* *}$ & 1.148 & $0.004^{* *}$ & 1.112 & $0.004^{* *}$ & 1.134 & $0.010^{* *}$ \\
\hline Attractive, $x_{\text {attract }}$ & 0.592 & $0.018^{*}$ & 0.814 & $0.001^{* *}$ & 0.535 & $0.033^{*}$ & 0.771 & $0.005^{* *}$ \\
\hline \multicolumn{9}{|l|}{ Control variables } \\
\hline Distance to coastline $(\mathrm{km}), w_{\text {dist }}$ & -0.006 & $0.001^{* * *}$ & -0.005 & $0.002^{* *}$ & -0.006 & $0.001^{* * *}$ & -0.004 & $0.006^{* *}$ \\
\hline Location in floodplain, $w_{f p}$ & 0.134 & 0.619 & -0.090 & 0.718 & - & - & - & - \\
\hline Perceived disruption, $w_{\text {perdis }}$ & -0.359 & 0.063 & -0.364 & $0.046^{*}$ & - & - & - & - \\
\hline Self Efficacy, $w_{\text {self }}$ & -0.483 & $0.017^{*}$ & -0.472 & $0.017^{*}$ & -0.437 & $0.031^{*}$ & -0.429 & $0.032^{*}$ \\
\hline Future tenure, $w_{\text {tenure }}$ & -0.243 & 0.305 & -0.187 & 0.390 & - & - & - & - \\
\hline Net worth $(\$ 1000 s), w_{n w}$ & -0.001 & 0.175 & -0.001 & 0.182 & - & - & - & - \\
\hline Race, $w_{\text {race }}$ & 0.252 & 0.381 & 0.231 & 0.376 & - & - & - & - \\
\hline Single male, $w_{m g l}{ }^{\mathrm{c}}$ & 0.309 & 0.394 & 0.281 & 0.408 & - & - & - & - \\
\hline Married, $w_{m g 2}{ }^{\mathrm{c}}$ & 0.293 & 0.316 & 0.313 & 0.236 & - & - & - & - \\
\hline Unemployed, $w_{\text {emplovl }}^{\mathrm{d}}$ & -0.076 & 0.893 & 0.062 & 0.904 & - & - & - & - \\
\hline
\end{tabular}


Table 5 (Continued)

\begin{tabular}{|c|c|c|c|c|c|c|c|c|}
\hline Retired/Unable to work, $w_{\text {employ } 2}{ }^{\mathrm{d}}$ & 0.059 & 0.776 & 0.129 & 0.497 & - & - & - & - \\
\hline Education, $w_{e d u c}$ & 0.184 & 0.366 & 0.113 & 0.544 & - & - & - & - \\
\hline \multicolumn{9}{|l|}{ Retrofit type variables, $z_{\text {type }} \mathrm{e}^{\mathrm{e}}$} \\
\hline Special foam adhesive under roof & -1.333 & $0.000^{* * *}$ & - & - & -1.329 & $0.001^{* * *}$ & - & - \\
\hline Hurricane shutters & -1.636 & $0.000^{* * *}$ & - & - & -1.644 & $0.000^{* * *}$ & - & - \\
\hline Impact resistant windows & -0.159 & 0.598 & - & - & -0.172 & 0.563 & - & - \\
\hline Hurricane straps/ties & -0.735 & $0.025^{*}$ & - & - & -0.725 & $0.028^{*}$ & - & - \\
\hline Elevated appliances & -3.062 & $0.000^{* * *}$ & - & - & -3.030 & $0.000^{* * *}$ & - & - \\
\hline Water resistant siding & 0.063 & 0.826 & - & - & 0.068 & 0.808 & - & - \\
\hline Home elevated on piles & -2.661 & $0.000^{* * *}$ & - & - & -2.652 & $0.000^{* * *}$ & - & - \\
\hline State dependence, $\varphi_{i}$ & -0.634 & $0.000^{* * *}$ & -0.558 & $0.000^{* * *}$ & -0.624 & $0.000^{* * *}$ & -0.569 & $0.000^{* * *}$ \\
\hline Std. dev. of state dependence & 0.423 & $0.000^{* * *}$ & 0.376 & $0.000^{* * *}$ & 0.423 & $0.000^{* * *}$ & 0.380 & $0.000^{* * *}$ \\
\hline Std. dev. of SP ASC, $\sigma$ & 0.523 & $0.000^{* * *}$ & 0.438 & $0.000^{* * *}$ & 0.355 & $0.000^{* * *}$ & 0.268 & $0.000^{* * *}$ \\
\hline SP scale relative to $\mathrm{RP}, \lambda$ & \multicolumn{2}{|c|}{2.451} & \multicolumn{2}{|c|}{2.928} & \multicolumn{2}{|c|}{3.611} & \multicolumn{2}{|c|}{4.794} \\
\hline Log-likelihood & \multicolumn{2}{|c|}{-757.360} & \multicolumn{2}{|c|}{-839.565} & \multicolumn{2}{|c|}{-762.384} & \multicolumn{2}{|c|}{-842.402} \\
\hline McFadden pseudo- $\mathrm{R}^{2}$ & \multicolumn{2}{|c|}{0.643} & \multicolumn{2}{|c|}{0.604} & \multicolumn{2}{|c|}{0.641} & \multicolumn{2}{|c|}{0.603} \\
\hline
\end{tabular}

a Signif. codes: $0{ }^{\prime * * * 1} 0.001^{\prime * * 1} 0.01^{\prime * 1} 0.05^{\prime \prime}$

${ }^{\mathrm{b}}$ Retrofit attribute variables are coded so that $x_{k}=1$ reflects a positive attitude (e.g., cost is not too high), and $x_{k}=0$ reflects a negative attitude (e.g., cost is too high) (Table 1)

${ }^{c} w_{m g}$ was coded to be Single female ( 0$)$ when $w_{m g l}=0$ and $w_{m g}=0$, Single male (1) when $w_{m g l}=1$ and $w_{m g 2}=0$, and Married (2) when $w_{m g l}=0$ and $w_{m g}=1$.

$\mathrm{d}{ }_{\text {employ }}$ was coded to be Employed when $w_{\text {employ } 1}=0$ and $w_{\text {employ } 2}=0$, Unemployed (1) when $w_{\text {employ } 1}=1$ and $w_{\text {employ } 2}=0$, and Retired/Unable to work $(2)$ when

$w_{\text {employ } 1}=0$ and $w_{\text {employ } 2}=1$.

${ }^{\mathrm{e}}$ Retrofit type was coded with seven binary dummy variables, using Wind resistant shingles as the reference. 
Four versions of the mixed logit model were fitted (Table 5). Model 1 includes all the variables in Equation 1 and Tables 1, 3, and 4. Model 2 is the same, but with the retrofit type variables, $\vec{z}_{t}$, omitted. Model 3 and 4 are the same as Models 1 and 2, respectively, but with all control variables that were not statistically significant in Model 1 ( $\mathrm{p}$-value $>0.05$ ) omitted.

The McFadden's pseudo- $R^{2}$ values (also called the likelihood ratio index) are computed as $\rho=1-\mathcal{L}(\hat{\beta}) / \mathcal{L}(0)$, where $\mathcal{L}(\hat{\beta})$ is the log-likelihood value of model with estimated parameters and $\mathcal{L}(0)$ is the log-likelihood value of model with ASCs only (Train 2009). The pseudo- $R^{2}$ values 0.60 to 0.64 suggest that all models fit the data well, the models with the retrofit type variables included fit the data better than those without, and removing the insignificant control variables makes little difference. In all models, the scale of SP relative to $\mathrm{RP}, \lambda$, was highly significant ( $\mathrm{p}<0.0001$ ), suggesting that it is important to allow the scale to differ. The SP-to-RP scale was greater than 1 (2.5 to 4.8$)$ in every model, indicating that the error variance in the SP choice context was lower than that in the RP choice context. The mean and standard deviation of the state dependence parameter, $\varphi_{i}$, are also highly significant $(\mathrm{p}<0.0001)$, meaning that an individual's past retrofit decisions (i.e., RP responses) influence their intentions to retrofit (i.e., SP responses). The values of $\varphi_{i}$ being negative (-0.63 to -0.56$)$ suggests that on average, people who said they retrofitted in the past were less likely to say they would in the future, and conversely, people who said they had not retrofitted in the past were more likely to say they would in the future (Bhat and Castelar 2002). One possible explanation is that, although we asked respondents to imagine they had moved to a new house, if an individual had retrofitted in the past, she might believe the home does not require additional strengthening in the future, and vice versa. Overall, these results suggest that it was important to include the RP-SP scale difference and state dependence in the model specifications. For the remainder of the section, we 
focus on Model 3 (with retrofit type variables included) and Model 4 (without retrofit type variables).

\subsection{RETROFIT ATTRIBUTES}

The percentage of people who retrofit varies a lot depending on the type of retrofit under consideration, from $3 \%$ to $16 \%(\mathrm{RP})$ and $8 \%$ to $50 \%(\mathrm{SP})$ depending on retrofit type (Table 2 ). The primary focus of this study is to identify attributes of those retrofits that help explain an individual's different attitudes across specific retrofits. This can inform policies aiming to increase takeup of retrofit efforts.

In both Models 3 and 4, all seven retrofit attributes under consideration were statistically significant at the $\mathrm{p}=0.001$ to $\mathrm{p}=0.09$ level for Model 3 and the $\mathrm{p}=0.0001$ to $\mathrm{p}=0.04$ level for

Model 4 (Table 5). Further, all of the retrofit attribute coefficients, $\vec{\beta}$, have positive signs, indicating agreement with the hypothesized effects (i.e., increased positive attitudes are associated with increased likelihood of retrofit).

In mixed logit models, the coefficient magnitudes are difficult to interpret directly, so we compute marginal effects to examine the relative importance of the retrofit attributes. A direct marginal effect is the effect of a unit change in a variable for alternative $j$ on the probability of choosing that alternative $j$. To compute them, we employed the probability weighted sample enumeration (PWSE), in which the marginal effect is calculated for each observation, then a weighted average is determined, with weights defined as the choice probabilities (Hensher et al. 2015). Figure 1 shows the marginal effects for each retrofit attribute and retrofit type, for Models 3 and 4. It suggests, for example, that changing an individual's perception of the cost of a retrofit from negative to positive (e.g., from Cost of retrofit is too high to Cost of retrofit is not too high) increases the probability of undertaking the retrofit by 0.08 according to Model 3 (or 0.10 for 
Model 4). For comparison, the raw data suggests that on average, the probability an individual would have done a retrofit is 0.095 (Table 2). Focusing on Model 4 without the retrofit type variable, overall, the results indicate that protects property and adds value to the home are the most important attributes; effort required is least important; and the other attributes are in the middle (Figure 1).

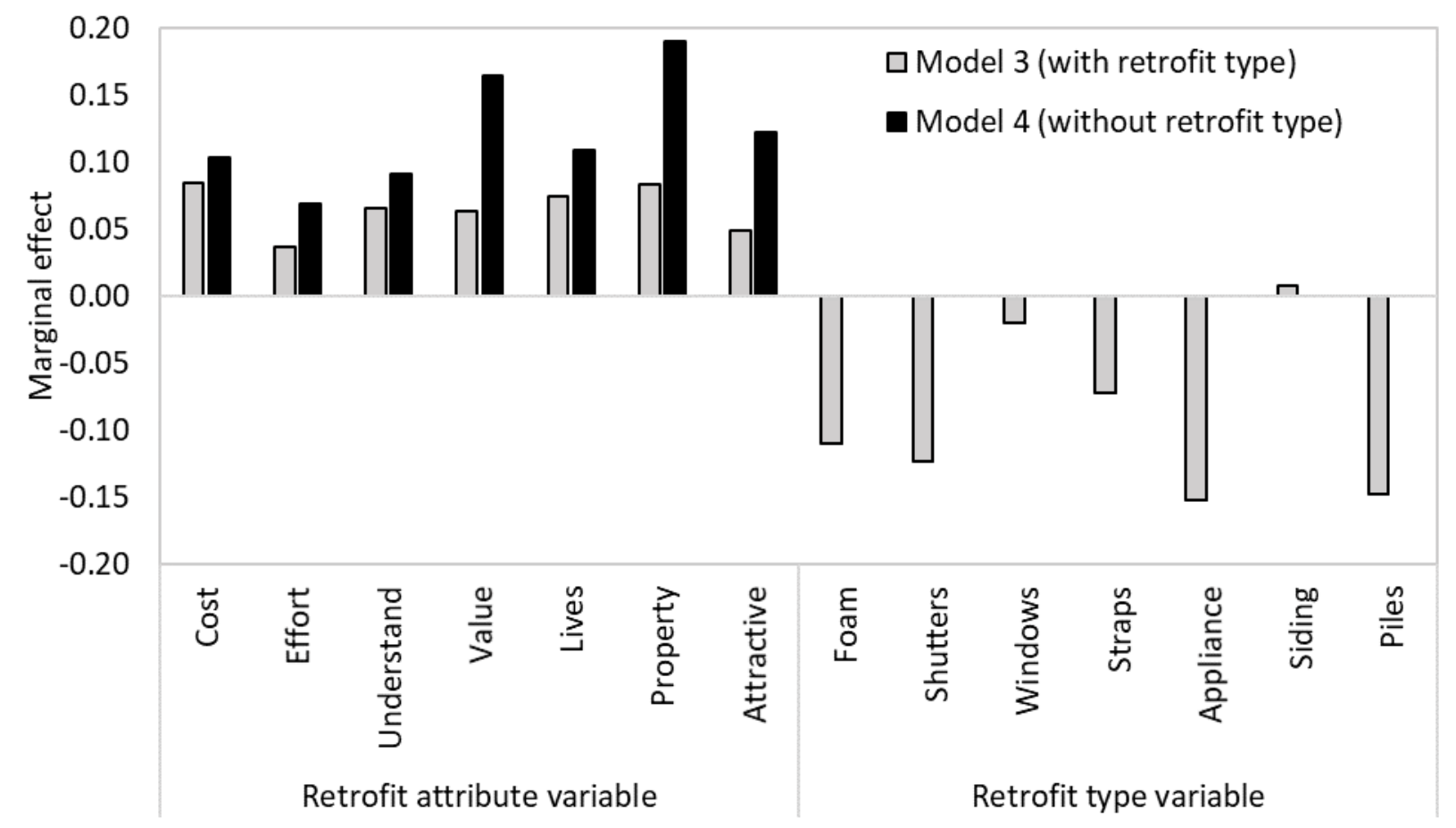

Figure 1. Marginal effects of variables for Model 3 (with retrofit type variables) and Model 4 (without retrofit type variables)

The potential to target perceptions of retrofit attributes to increase retrofit implementation depends both on the marginal effect of the attribute and the extent to which there is room for improvement (i.e., the percentage of the population that currently thinks negatively and whose opinions could be targeted for change). Figure 1 and Table 2 together suggest, for example, that adding value to the home is important and across all retrofit types, many have a negative perception of it and therefore, changing opinions related to the value added to the home could be an effective way to increase retrofitting. For property protection, on the other hand, while it has a 
large marginal effect, most people already feel positively about it. On the other hand, many feel negatively about effort required, but changing that view is not expected to have as great an effect as changing perceptions of the other attributes (Figure 1). Table 2 also includes information about perceptions for specific retrofit types, which could be used to further finetune policy interventions. For example, though people feel relatively positively about the ability of retrofits to protect property in general (68\%) that is less so for elevating appliances (48\%), suggesting a narrower opportunity to capitalize on the relatively high marginal effect of property protection efficacy.

\subsection{RETROFIT TYPES}

The aim of this study was to develop a homeowner retrofit prediction model that would capture the differences in specific retrofit types by including the characteristics of those types that influence the homeowner decision to undertake them. If all relevant retrofit attributes are included, the model should be generally applicable to any retrofit type and there should be no need to identify the retrofit type beyond its key attributes.

To test the assumption that the list of retrofit attributes we have included (cost, effort, understanding, value added, life protection, property protection, and attractiveness) are all the ones that influence the retrofit decision, we compare models with and without the retrofit type indicator variables included (Models 3 and 4). A log-likelihood ratio test comparing Models 3 and 4 (p-value $<0.0001$ ) indicates that Model 3 does fit the data better than Model 4. Further, while the coefficients of the impact resistant windows and water resistant siding retrofit types in Model 3 are not statistically significant, the other five are, suggesting that changing from a decision concerning wind resistant shingles (the reference retrofit type) to one associated with implementing foam adhesive, hurricane shutters, hurricane straps/ties, elevated appliances, or 
elevated home on piles would change the probability of undertaking the retrofit (Table 5). In particular, even given the variability captured in the seven retrofit attributes, the probability of retrofitting is different for different retrofit types. Specifically, the Model 3 results indicate that the order of retrofit types from least to most likely to be done is elevated appliances, home elevated on piles, hurricane shutters, special foam adhesive under roof, hurricane straps/ties, and finally, impact resistant windows, water resistant siding, and wind resistant shingles are tied for most likely.

There are at least two possible explanations for the statistical significance of the retrofit type variables. First, there may be additional attributes of the retrofits that are important for the retrofit decision and that we have not included, such as, requires a lot of cooperation from others or useful for other purposes (Terpstra and Lindell 2012). Second, it may be that the relationships between the probability of retrofitting and the perception of the retrofit attributes are nonlinear and operationalizing the retrofit attributes as simple binary variables does not fully capture them. For example, it may be that people think not just that the cost of hurricane straps/ties is too high and the cost of elevating a home on piles is too high, but that the former is a little too high and the latter is way too high. If that was the case, then the variability between perception of cost of hurricane straps/ties and perception of cost of elevating the home, which the cost variable cannot capture, could be captured instead by the home elevated on piles retrofit type variable. Some of this type of interaction between the retrofit type and retrofit attribute variables is evident. When the retrofit type variables are removed in Model 4, for example, some of the variability they captured appears to be captured by the retrofit attributes instead. For example, elevated appliances and home elevated on piles are the retrofit type variables with the largest coefficients $\left(\delta_{\text {appliances }}=-3.03\right.$ and $\left.\delta_{\text {elevhome }}=-2.65\right)$. They also have the lowest two values for value 
added $\left(x_{\text {value }}\right)$ and attractiveness $\left(x_{\text {attract }}\right)$ (Table 2$)$. When the elevated appliances and home elevated on piles retrofit type variables are removed going from Model 3 to Model 4, the magnitudes of the coefficients of $x_{\text {value }}$ and $x_{\text {attract }}$ are increased. This can also be seen by comparing the Value and Attractive marginal effects for Models 3 and 4. They are much higher in Model 4 when Retrofit type is not included. Future work could explore both of these possible explanations. In any case, although Model 3 is preferred to Model 4 in terms of statistical significance, the models are similar and have similar pseudo- $R^{2}$ values, suggesting that Model 4 is a reasonable model as well.

\subsection{CONTROL VARIABLES}

Of the ten individual-specific control variables considered, only two were statistically significant at the 0.05 level when all variables were included (Model 1), and therefore were retained in Models 3 and 4 (Table 5). Distance to coastline, $w_{\text {dist }}$, had the expected effect, with a greater distance to the coastline being associated with a smaller probability of retrofitting, perhaps because people farther from the coast perceive they are at lower risk. The negative coefficient self-efficacy, $w_{\text {self }}$, however indicates that individuals who believe personal actions matter in determining damage were less likely to retrofit, which is counterintuitive. Thinking that Location in floodplain, $w_{f p}$, might not be significant because five of the eight retrofit types aim to reduce wind-related damage as opposed to flood-related damage, we tried fitting models using only observations associated with the flood-related retrofit types. In those cases, Location in floodplain, $w_{f p}$, was still not statistically significant ( $\mathrm{p}$-value $=0.23$ or 0.37 when all control variables were included, or only those that were significant at 0.05 level, respectively). 


\section{CHAPTER 6}

\section{DISCUSSION}

Focusing on hurricane-related home retrofits in particular, this study offers evidence that people's perceptions of protective action attributes influences the likelihood they will undertake the action. Specifically, we found evidence supporting the hypotheses that a higher probability of undertaking a retrofit is associated with homeowner beliefs that: (1) the retrofit cost is not too high, (2) the installation does not require too much effort, (3) they understand how it works, (4) it would add to home value, (5) it would protect lives, (6) it would protect property, and (7) would not make the home less attractive. In addition, 25\% (attractiveness) to 59\% (cost) of respondents had a negative impression of the attributes, indicating some opportunity to improve those perceptions.

Since perceptions of these attributes vary across possible physical home retrofits as well as other types of protective actions, these findings have implications for interpretation of other studies. The results encourage caution in generalizing conclusions about protective action decision-making. Conclusions drawn from a study of one type of protective action (e.g., having an emergency kit) may not apply to other types of protective actions (e.g., adding hurricane shutters).

The results also have policy implications. First, there are likely ways to influence decision-makers beyond economic incentives. Efforts to modify the other retrofit characteristics and/or the perceptions of those characteristics could affect takeup rates. This could include programs to reduce the effort required to undertake a retrofit by designing new easier-to-install retrofits and/or streamlining the process necessary to find and hire someone to do it. It could 
include education programs to help people understand how a mitigation action works to reduce damage and/or improve safety. Initiatives that help investments in retrofits add value to the home could increase takeup rates as well. Second, it is important for policy makers to recognize the variability across retrofit types and people. The effectiveness of policy interventions may vary by retrofit type. Many available public policy programs to encourage retrofits focus on a particular retrofit type (Chiew et al. in review reviews existing incentive programs). To the extent possible, those that appeal to the most homeowners and will provide the best risk reduction should be highlighted.

Finally, this study suggests a few avenues of future research. Investigation of a broader range of protective actions beyond hurricane-related retrofits can help determine if similar patterns hold for other types of retrofits. It would be useful to examine the possibility of a nonlinear relationship between the probability of retrofit and the perceived attribute by operationalizing perceived retrofit attributes as multilevel or continuous variables and exploring nonlinear variable transformations. Where appropriate (e.g., cost, property loss reduction effectiveness), additional study of the relationship between the perceptions of protective action attributes and objectively measured values of the attributes. Future studies can benefit from a combination of RP and SP data like that used in this study, allowing increased variability across retrofit attribute levels to facilitate estimation of coefficients and estimation of constants based on RP data to minimize possible biases associated with behavioral intentions vs. actual observed behaviors. 


\section{REFERENCES}

Ajzen, I. (1991). The theory of planned behavior. Organizational Behavior and Human Decision Processes, 50, 179-211.

American Association for Public Opinion Research, (2019). Response rates-An overview. Accessed 20 May 2019, https://www.aapor.org/Education-Resources/For-Researchers/PollSurvey-FAQ/Response-Rates-An-Overview.aspx.

Bhat, C. R., \& Castelar, S. (2002). A unified mixed logit framework for modeling revealed and stated preferences: formulation and application to congestion pricing analysis in the San Francisco Bay area. Transportation Research Part B: Methodological, 36(7), 593-616.

Botzen, W. J., Aerts, J. C., \& van den Bergh, J. C. (2013). Individual preferences for reducing flood risk to near zero through elevation. Mitigation and Adaptation Strategies for Global Change, 18(2), 229-244.

Botzen, W. J., Aerts, J. C., \& van den Bergh, J. C. (2009). Willingness of homeowners to mitigate climate risk through insurance. Ecological Economics, 68(8-9), 2265-2277.

Botzen, W. J., \& van den Bergh, J. C. (2012). Risk attitudes to low-probability climate change risks: WTP for flood insurance. Journal of Economic Behavior \& Organization, 82(1), 151166.

Brody, S. D., Highfield, W. E., Wilson, M., Lindell, M. K., \& Blessing, R. (2017). Understanding the motivations of coastal residents to voluntarily purchase federal flood insurance. Journal of Risk Research, 20(6), 760-775.

Bubeck, P., Botzen, W. J., \& Aerts, J. C. (2012). A review of risk perceptions and other factors that influence flood mitigation behavior. Risk Analysis: An International Journal, 32(9), 1481-1495.

California Seismic Safety Commission (CSSC). (2009). The Study of Household Preparedness: Preparing California for Earthquakes. Final Report by the Alfred E. Alquist Seismic Safety Commission to the California State Legislature, CSSC 09-03, July.

Carson, J. M., McCullough, K. A., \& Pooser, D. M. (2013). Deciding whether to invest in mitigation measures: evidence from Florida. Journal of Risk and Insurance, 80(2), 309-327.

Chiew, E., Davidson, R. A., Trainor, J. E., Nozick, L., \& Kruse, J. (in review). The impact of grants on homeowner decisions to retrofit to reduce hurricane-induced wind and flood damage. Weather, Climate, and Society.

Daellenbach, K., Parkinson, J., \& Krisjanous, J. (2018). Just how prepared are you? An application of marketing segmentation and theory of planned behavior for disaster preparation. Journal of Nonprofit \& Public Sector Marketing, 30(4), 413-443. 
De Boer, J., Wouter Botzen, W. J., \& Terpstra, T. (2015). More than fear induction: Toward an understanding of people's motivation to be well-prepared for emergencies in flood-prone areas. Risk analysis, 35(3), 518-535.

Dillman, D. A., (2007). Mail and internet surveys - the tailored design method, 2nd ed. Wiley.

Floyd, D. L., Prentice-Dunn, S., \& Rogers, R. W. (2000). A meta-analysis of research on protection motivation theory. Journal of applied social psychology, 30(2), 407-429.

Ge, Y., Peacock, W. G., \& Lindell, M. K. (2011). Florida households' expected responses to hurricane hazard mitigation incentives. Risk Analysis: An International Journal, 31(10), 1676-1691.

Grothmann, T., \& Reusswig, F. (2006). People at risk of flooding: why some residents take precautionary action while others do not. Natural hazards, 38(1-2), 101-120.

Harrell Jr, F. E. (2015). Regression modeling strategies: with applications to linear models, logistic and ordinal regression, and survival analysis. Springer.

Hensher, D. A., Rose, J. M., \& Greene, W. H. (2015). Applied choice analysis. 2nd ed. Cambridge, UK: Cambridge University Press.

Hensher, D. A., Rose, J. M., \& Greene, W. H. (2008). Combining RP and SP data: biases in using the nested logit 'trick'-contrasts with flexible mixed logit incorporating panel and scale effects. Journal of Transport Geography, 16(2), 126-133.

Insurance Institute for Business \& Home Safety (IBHS). (2017). Build strong. Build FORTIFIED. Accessed February 9, 2017. https://disastersafety.org/fortified.

Jasour, Z., A. Davidson, R., E. Trainor, J., L. Kruse, J., \& K. Nozick, L. (2018). Homeowner decisions to retrofit to reduce hurricane-induced wind and flood damage. Journal of Infrastructure Systems, 24(4), 04018026.

Kreibich, H., Thieken, A. H., Petrow, T., Müller, M., \& Merz, B. (2005). Flood loss reduction of private households due to building precautionary measures - lessons learned from the Elbe flood in August 2002. Nat. Hazards Earth Syst. Sci., 5(1), 117-126.

Kunreuther, H., Onculer, A., \& Slovic, P. (1998). Time insensitivity for protective investments. Journal of Risk and Uncertainty, 16(3), 279-299.

Langer, E. J. (1975). The Illusion of Control. Journal of Personality and Social Psychology, 32(2), 311-328.

Lindell, M. K., Arlikatti, S., \& Prater, C. S. (2009). Why people do what they do to protect against earthquake risk: Perceptions of hazard adjustment attributes. Risk Analysis: An International Journal, 29(8), 1072-1088. 
Lindell, M. K., \& Hwang, S. N. (2008). Households' perceived personal risk and responses in a multihazard environment. Risk Analysis: An International Journal, 28(2), 539-556.

Lindell, M. K., \& Perry, R. W. (2012). The protective action decision model: theoretical modifications and additional evidence. Risk Analysis: An International Journal, 32(4), 616632.

Lindell, M. K., \& Perry, R. W. (2000). Household adjustment to earthquake hazard: A review of research. Environment and behavior, 32(4), 461-501.

Lindell, M. K., \& Prater, C. S. (2002). Risk Area Residents' Perceptions and Adoption of Seismic Hazard Adjustments 1. Journal of Applied Social Psychology, 32(11), 2377-2392.

Lindell, M. K., \& Whitney, D. J. (2000). Correlates of household seismic hazard adjustment adoption. Risk analysis, 20(1), 13-26.

Liu, T., \& Jiao, H. (2018). Insights into the effects of cognitive factors and risk attitudes on fire risk mitigation behavior. Computational Economics, 52(4), 1213-1232.

Marketing Systems Group, (2018). GENESYS. Accessed 28 November 2018, https://www.m-sg.com/Pages/genesys/.

McClelland, G., Schulze, W., Coursey, D. (1993). Insurance for Low-Probability Hazards: A Bimodal Response to Unlikely Events. Journal of Risk and Uncertainty, 7, 95-116.

McClure, J., Spittal, M. J., Fischer, R., \& Charleson, A. (2014). Why do people take fewer damage mitigation actions than survival actions? Other factors outweigh cost. Natural Hazards Review, 16(2), 04014018.

Osberghaus, D. (2015). The determinants of private flood mitigation measures in GermanyEvidence from a nationwide survey. Ecological Economics, 110, 36-50.

Peacock, W. G. (2003). Hurricane mitigation status and factors influencing mitigation status among Florida's single-family homeowners. Natural Hazards Review, 4(3), 149-158.

Petrolia, D. R., Hwang, J., Landry, C. E., \& Coble, K. H. (2015). Wind insurance and mitigation in the coastal zone. Land Economics, 91(2), 272-295.

Poussin, J. K., Botzen, W. W., \& Aerts, J. C. (2015). Effectiveness of flood damage mitigation measures: Empirical evidence from French flood disasters. Global Environmental Change, $31,74-84$.

Poussin, J. K., Botzen, W. W., \& Aerts, J. C. (2014). Factors of influence on flood damage mitigation behaviour by households. Environmental Science \& Policy, 40, 69-77.

Ramirez, K. (2017, November 14). Here's what today's first-time homebuyer looks like. Housingwire. Retrieved from www.housingwire.com/articles/41813-heres-what-todays-firsttime-homebuyer-looks-like 
Sarrias, M., \& Daziano, R. (2017). Multinomial Logit Models with Continuous and Discrete Individual Heterogeneity in R: The gmnl Package. Journal of Statistical Software, 79(2), 146.

Savitt, A. (2017). Insurance as a tool for hazard risk management? An evaluation of the literature. Natural hazards, 86(2), 583-599.

Taggart, M., \& van de Lindt, J. W. (2009). Performance-based design of residential wood-frame buildings for flood based on manageable loss. Journal of performance of constructed facilities, 23(2), 56-64.

Terpstra, T., \& Lindell, M. K. (2013). Citizens' perceptions of flood hazard adjustments: an application of the protective action decision model. Environment and Behavior, 45(8), 9931018.

Thieken, A. H., Petrow, T., Kreibich, H., \& Merz, B. (2006). Insurability and mitigation of flood losses in private households in Germany. Risk Analysis: An International Journal, 26(2), 383-395.

Train, K. E. (2009). Discrete choice methods with simulation. Cambridge university press.

Van Buuren, S. (2018). Flexible imputation of missing data. Chapman and Hall/CRC.

Van Buuren, S., \& Groothuis-Oudshoorn, K. (2010). mice: Multivariate imputation by chained equations in R. Journal of statistical software, 1-68.

White, I. R., Royston, P., \& Wood, A. M. (2011). Multiple imputation using chained equations: issues and guidance for practice. Statistics in medicine, 30(4), 377-399. 